\title{
Hfq affects mRNA levels independently of degradation
}

\author{
Jacques Le Derout ${ }^{1}$, Irina V Boni ${ }^{2}$, Philippe Régnier ${ }^{1}$, Eliane Hajnsdorf ${ }^{{ }^{*}}$
}

\begin{abstract}
Background: The bacterial Lsm protein, Hfq, is an RNA chaperone involved in many reactions related to RNA metabolism, such as replication and stability, control of small RNA activity and polyadenylation. Despite this wide spectrum of known functions, the global role of $\mathrm{Hfq}$ is almost certainly undervalued; its capacity to bind DNA and to interact with many other proteins are only now beginning to be taken into account.

Results: The role of $\mathrm{Hfq}$ in the maturation and degradation of the $r p s \mathrm{O}$ RNA of E. coli was investigated in vivo. The data revealed a decrease in rpsO mRNA abundance concomitant to an increase in its stability when $\mathrm{Hfq}$ is absent. This indicates that the change in mRNA levels in hfa mutants does not result from its modification of RNA stability. Moreover, a series of independent experiments have revealed that the decrease in mRNA level is not a consequence of a reduction of translation efficiency and that Hfq is not directly implicated in translational control of $r p s O$ expression. Reduced steady-state mRNA levels in the absence of $\mathrm{Hfq}$ were also shown for rpsT, rpsB and rpsB-tsf, but not for Ipp, pnp or tRNA transcripts. The abundance of chimeric transcripts rpsO-lacZ and rpsB-lacZ, whose expression was driven by rps $O$ and rpsB promoters, respectively, was also lower in the hfq null-mutants, while the $\beta$-galactosidase yield remained about the same as in the parent wild-type strain.

Conclusions: The data obtained suggest that alteration of rpsO, rpsT and rpsB-tsf transcript levels observed under conditions of Hfa deficiency is not caused by the post-transcriptional events, such as mRNA destabilization or changes in translation control, and may rather result from changes in transcriptional activity. So far, how Hfq affects transcription remains unclear. We propose that one of the likely mechanisms of Hfq-mediated modulation of transcription might operate early in the elongation step, when interaction of Hfq with a nascent transcript would help to overcome transcription pauses and to prevent preliminary transcript release.
\end{abstract}

\section{Background}

Hfq is an RNA binding protein initially identified as a host factor required for the replication of the phage $Q \beta$ RNA [1]. It was then demonstrated to belong to the Sm-like protein family involved in many RNA processing events in eukaryotes [2]. The Hfq-encoding gene is widely conserved in bacteria and found in many sequenced bacterial genomes [3]. Hfq is a highly abundant protein considered to act as a global regulator of gene expression $[4,5]$. It has recently received much attention because of its crucial role in diverse cellular processes controlled by small non-coding RNAs (ncRNAs), where Hfq facilitates pairing of ncRNAs with

\footnotetext{
* Correspondence: Eliane.Hajnsdorf@ibpc.fr

1UPR CNRS n 9073, conventionnée avec I'Université Paris 7 - Denis Diderot Institut de Biologie Physico-Chimique, 13 rue Pierre et Marie Curie, 75005
} Paris, France their target mRNAs [6-9]. This explains, at least partly, why inactivation of the $h f q$ gene causes pleiotropic phenotypes [5]. Some of changes in the gene expression pattern are related to reduced translation efficiency of the rpoS mRNA, encoding the major stress sigma factor $\sigma^{\mathrm{S}}[4,10]$, others to the induction of the $\sigma^{\mathrm{E}}$-mediated envelope stress response [11-13] and the deficiency of the $\sigma^{\mathrm{H}}$-mediated cytoplasmic stress response [12].

In addition, Hfq may affect some processes through its direct interaction with RNAs, e.g. with $\mathrm{Q} \beta$ phage RNA during replication $[14,15]$ or with its own mRNA where it acts as a translational autorepressor [16,17]. Hfq interactions with tRNAs [18,19] and tRNA precursors [20] have also been reported.

Hfq function in the cell may also be mediated by protein-protein contacts. Hfq has been reported to interact with numerous proteins including ribosomal proteins,
C Biomed Central

(c) 2010 Le Derout et al; licensee BioMed Central Ltd. This is an Open Access article distributed under the terms of the Creative Commons Attribution License (http://creativecommons.org/licenses/by/2.0), which permits unrestricted use, distribution, and reproduction in any medium, provided the original work is properly cited. 
RNases, helicases, Rho-factor, RNA polymerase (in the presence of S1 protein), protein H-NS and poly(A)polymerase (PAP I) [21-25]. Related to the last observation, we have also shown that Hfq stimulates PAP I mediated synthesis of poly(A) tails by promoting the processivity of the enzyme and by protecting the poly(A) tails from exoribonucleolytic degradation [26-29]. Finally, Hfq has also been identified as a DNA binding protein that preferentially binds curved DNA and affects negative supercoiling $[5,30,31]$. However, in a cell, the majority of $\mathrm{Hfq}$ is located in the cytoplasm, presumably in association with the translation machinery, and only a minor fraction is associated with the nucleoid [32].

In the present work, our initial goal was to investigate the role of $\mathrm{Hfq}$ in the maturation and degradation of the rpsO mRNA of $E$. coli in vivo. The degradation pathway of the $r p s O$ transcript, coding for ribosomal protein S15, is one of the best understood decay-pathways in $E$. coli. The genes encoding ribosomal protein $\mathrm{S} 15$ ( $r p s O)$ and polynucleotide phosphorylase ( $p n p)$ occupy adjacent positions and are oriented in the same direction on the E. coli chromosome. The two genes have their own promoters, P1 and P2 respectively, and can be expressed as monocistronic transcripts or as an rpsO-pnp dicistronic transcript. In this latter case, an endonucleolytic cleavage by RNase III produces a P1-RIII rpsO mRNA slightly longer than the P1-t1 rpsO monocistronic transcript $[33,34]$. The initial step in the degradation of the rps $O$ mRNA is an RNase E cleavage that generates RNA molecules lacking the Rho-independent terminator, which are then rapidly degraded by the 3' to 5' exonucleases PNPase and RNase II [35-37]. The rpsO mRNA is stabilized by efficient translation because terminating ribosomes occlude the site for the rate-limiting RNase E cleavage located 10 nucleotides downstream of the translation termination codon [38]. Since ribosomal protein S15 autoregulates its synthesis at the posttranscriptional level by repressing its own translation [39] and thereby decreasing the number of ribosomes translating the $\operatorname{rps} O$ mRNA, it has been proposed that the coupling of the mRNA stability to translation allows the cell to adapt the amount of the rpsO mRNA to the need for ribosomal protein S15. Besides the RNase E-mediated pathway, exonucleolytic poly(A)-dependent degradation also plays a significant role, which becomes predominant when RNase $\mathrm{E}$ is inactivated [40-42]. Although the regulation of the $r p s O$ gene expression was studied primarily at the posttranscriptional level, its transcription is most likely also modulated. However, while transcriptional start points have been identified precisely [33], transcriptional control remains largely unexplored.

Experiments were initiated to examine whether $\mathrm{Hfq}$ interferes with the rpsO mRNA decay mediated by RNase E or polyadenylation in vivo, as was previously shown in vitro [29]. Unexpectedly, we found that $\mathrm{Hfq}$ deficiency induces a decrease in $r p s O$ mRNA abundance concomitant to an increase in its stability. We present here a set of data suggesting that in the case of rpsO and some other cases, modulation of gene expression observed upon Hfq deficiency may result from changes in transcriptional yield.

\section{Results}

\section{Inactivation of $h f q$ reduces the level of the rpsO mRNA}

To determine whether Hfq affects the abundance and the decay-rate of the rpsO mRNA in vivo, we determined the stability of the corresponding transcripts in a set of isogenic wt $\left(h f q^{+}\right), h f q^{-}$and Hfq overproducing strains containing pTX367 [5], a pGEM3 derivative expressing the $h f q$ gene from its own promoter. The decay-rate of the rpsO mRNA was measured after inhibition of transcription by rifampicin. The more abundant mRNA species detected on Northern blots are the 420 nucleotide monocistronic transcript (P1-t1) and the 502 nucleotide RNase III-processed rpsO-pnp mRNA (P1-RIII). Fig. 1 shows that amounts of both rpsO transcripts are more abundant in the $h f q^{+}$strain than in the $h f q^{-}$mutant. There is in fact 10 times more P1-t1 mRNA in the wild type strain than in the $h f q$ mutant, and 2.2 times more in $h f q^{+} / \mathrm{pTX} 367$ overproducing cells than in the wild type bacteria transformed with the empty vector (compare time 0 in rifampicin experiments). Surprisingly, this drop in intracellular concentration is associated with stabilization expected to cause an accumulation of the $\operatorname{rps} O$ transcript. Indeed the half-life of the rpsO mRNA is significantly longer in the $h f q$ mutant $(1.79+/-0.13 \mathrm{~min})$ than in the wild type strain $(0.98+/-0.12 \mathrm{~min})$, thus confirming that Hfq can activate RNA decay [25]. The fact that no difference in stability was observed when $\mathrm{Hfq}$ was overproduced (half-life $0.98+/-0.16 \mathrm{~min}$ ) relative to the control strain (half-life $1.17+/-0.14 \mathrm{~min}$ ), suggests that the Hfq level in the wt strain is sufficient to exert a maximum destabilizing effect on the $\operatorname{rps} O$ mRNA decay (Fig. 1 and Table 1). The data above clearly indicate that the drop in $\operatorname{rps} O$ mRNA levels associated with Hfq deficiency does not result from its destabilization. On the contrary, we observed an increase in the rpsO mRNA stability, which should, in theory, result in its accumulation. It means that the drop in the rpsO mRNA level is, in fact, partially compensated by its stabilization.

\section{Hfq interferes with the poly(A) dependent degradation of} the rpsO mRNA in vivo

Previous investigations suggested that Hfq could affect rpsO mRNA stability by modulating both the poly(A)dependent and the RNase E-mediated degradation 


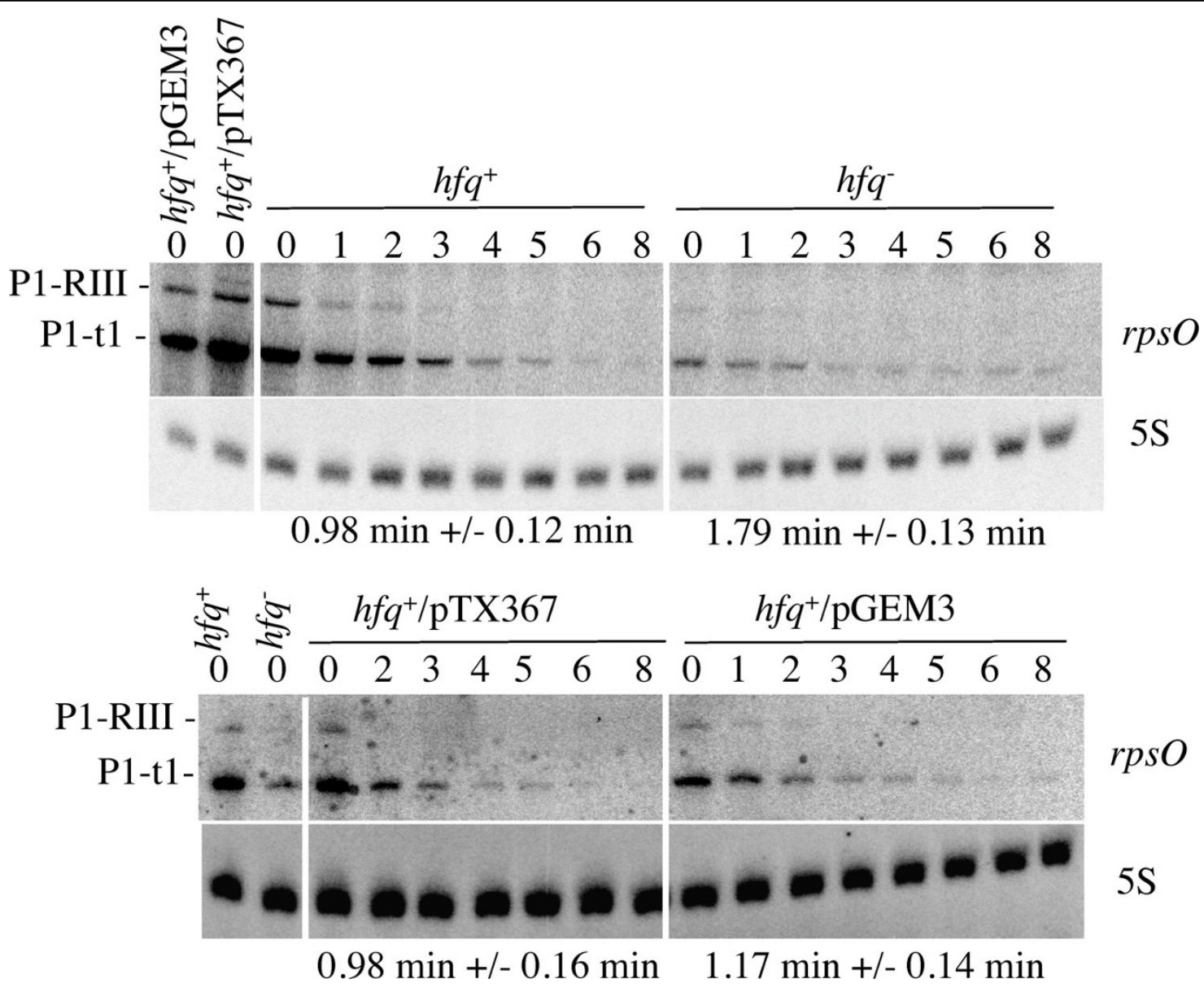

Figure 1 Effects of $\mathbf{H f q}$ inactivation on the stability and the abundance of the rpsO transcripts. Comparison of the decay-rate of the $r p s O$ mRNA in strains N3433 (wt), IBPC929 (hfa), N3433/pTX367 and N3433/pGEM3. Cultures were grown at $37^{\circ} \mathrm{C}$ to $\mathrm{OD}_{600} \approx 0.4$, RNA was extracted from aliquots withdrawn after addition of rifampicin $(500 \mathrm{\mu g} / \mathrm{ml}$ ) (time intervals in min are indicated above the lanes) and then subjected to Northern blot analysis. The blots were hybridized with the $r p s O$ probe and then with the probe for $5 S$ RNA to normalize the RNA content per lane. RNA levels were quantified using a Phospholmager; half-lives are indicated below each autoradiograph. Antibiotics were added when required.

Table 1 Variation and stability of the $r p s O, r p s O \Delta$ and $r p s T$ transcripts as a function of Hfq quantity.

\begin{tabular}{|c|c|c|c|c|}
\hline \multirow[b]{2}{*}{ Strains } & \multicolumn{2}{|r|}{ rpsO mRNA $\left(^{* *}\right)$} & \multicolumn{2}{|r|}{ rpsO $\triangle$ mRNA $(* *)$} \\
\hline & $\mathrm{t} 1 / 2(\min )\left(^{*}\right)$ & Relative RNA abundance at $\mathrm{T}=0$ & $\mathrm{t} 1 / 2(\min )(*)$ & Relative RNA abundance at $\mathrm{T}=0$ \\
\hline wt & $0.98+/-0.12$ & 100 & & \\
\hline$h f q$ & $1.79+/-0.13$ & 10.3 & & \\
\hline wt/pGEM3 & $1.17+/-0.14$ & 100 & & \\
\hline wt/pTX367 & $0.98+/-0.16$ & 222 & & \\
\hline$w t / p \triangle S 15 A \cup G$ & $1.13+/-0.1$ & 100 & $3.16+/-0.07$ & 100 \\
\hline \multirow[t]{2}{*}{$h f q / p \triangle S 15 A \cup G$} & $2.09+/-0.12$ & 50 & $4.67+/-0.09$ & 62.5 \\
\hline & & $r p s T$ mRNA & & \\
\hline Strains & $\mathrm{t} 1 / 2(\min )\left({ }^{*}\right)$ & Relative RNA abundance at $T=0$ & & \\
\hline wt P1-t1 & $1.31+/-0.17$ & 100 & & \\
\hline wt P2-t1 & $1.57+/-0.17$ & 100 & & \\
\hline hfq P1-t1 & $2.42+/-0.12$ & 66.7 & & \\
\hline hfq P2-t1 & $5.43+/-0.07$ & 16.9 & & \\
\hline
\end{tabular}

$\left({ }^{*}\right)$ Half-lives of transcripts were measured in strains N3433 (wt) and IBPC929 (hfq), transformed, when indicated, with pGEM3 empty vector, its derivative pTX367 expressing the $h f q$ gene, or with plasmid $\mathrm{p} \triangle \mathrm{S} 15 \mathrm{AUG}$ bearing the constitutively expressed truncated $r p s \mathrm{O}$ gene.

${ }^{* *}$ ) The $r p s O$ and the $r p s O \Delta$ transcripts originated from the chromosome and the $\mathrm{p} \Delta \mathrm{S} 15 \mathrm{AUG}$ plasmid, respectively. 
pathways. Besides its stimulating effect on the synthesis of poly(A) tails, Hfq was shown to protect poly(A) tails from exoribonucleolytic degradation in vitro and to affect the length and the frequency of oligo(A) tails in vivo [26-29]. Moreover, Hfq was found to protect the rpsO mRNA from RNase E cleavage in vitro [29]. To evaluate the role of Hfq in the poly(A)- and the RNase E-dependent degradation pathways in vivo, we compared the stability of the rpsO transcript in $h f q^{+}$and $h f q$-deficient strains when either of these pathways was inactivated. For this purpose, we used the $p c n B$ null-mutation to fully inactivate poly(A) polymerase and the rne3071 allele allowing inactivation of thermosensitive RNase E at the non permissive temperature.
Fig. 2A shows that Hfq has no significant impact on the decay-rate of the P1-t1 rpsO transcript in $p c n B$ cells. Half lives are $1.32+/-0.09 \mathrm{~min}$ in $h f q^{+}$and $1.39+/-$ $0.10 \mathrm{~min}$ in $h f q^{-}$in the first phase of the decay (time 0 to $4 \mathrm{~min}$ ) and, in contrast to what happens in $p c n B^{+}$ cells, that rpsO mRNA seems to be slightly more stable in the $h f q^{-}$strain 4 min after rifampicin addition. Moreover, the drop in the rpsO mRNA concentration resulting from Hfq inactivation is less marked in the absence of PAP I (2.3 times instead of 10 times in the PAP Icontaining cells).

These data suggest that Hfq does not significantly affect the RNase E dependent degradation pathway, which accounts for RNA decay in the $p c n B$ null-mutant


Figure 2 Impact of $\mathbf{H f q}$ on rpsO mRNA degradation pathways. Comparison of the rpsO mRNA abundance and stability in pcnB (A) and rne3071 (B) mutants bearing $h f q^{+}$or $h f q 1$ alleles. (A) Cells were grown at $37^{\circ} \mathrm{C}$. (B) Cells were grown at $30^{\circ} \mathrm{C}$ and shifted to $44^{\circ} \mathrm{C}$ to inactivate thermosensitive RNase $\mathrm{E}$ just before the addition of rifampicin. Northern-blot analysis was performed as described in the legend to Fig.1. Time intervals ( $\mathrm{min}$ ) after treating the cultures with rifampicin are indicated above the lanes. Below each Northern blots, relative amounts of the rps $\mathrm{O}$ mRNA (normalized to 5S RNA) for 0 time (before treating with rifampicin) are indicated. Time points 0 to 4 min and 0 to 16 min. were used to calculate the half-lives in the $p c n B$ mutants (Fig. 2A) and rne strains (Fig. 2B) respectively. 
[40]. Moreover, if extended to other strains, this conclusion implies that the stabilization that occurs in $h f q^{-}$ cells may not result from the impairment of the RNase E-mediated pathway. It is therefore likely, that changes of $r p s O$ mRNA stability and concentration described above require active PAP I; a prediction which prompted us to verify how Hfq affects the decay-rate of the $\mathrm{rps}_{\mathrm{O}}$ transcript when thermosensitive RNase E was inactivated.

We have ascertained that polyadenylation contributes to degradation of the rps $O$ mRNA in the absence of RNase E. As expected, the rpsO P1-t1 transcript was significantly stabilized when thermosensitive RNase E was inactivated [35]. Moreover, Hfq had a strong effect on the $\operatorname{rps} O$ mRNA abundance. While the stability of the P1-t1 transcript rose from $6.99+/-0.14 \mathrm{~min}$. to 11.18 $+/-0.14 \mathrm{~min}$. the steady-state amount of the transcript was reduced 7.7 times in the absence of $\mathrm{Hfq}$ (Fig. 2B). These data reinforce the hypothesis above that Hfq deficiency has a stabilizing effect on the rpsO mRNA, which in theory should cause an accumulation of RNA. However, this stabilization is completely masked by a drop in mRNA concentration whose origin is independent of RNA stability. Moreover, they also confirm that the extent of the impact of Hfq on RNA stabilization and concentration depends on the presence of PAP I in the cell. It is worth noting again, that this effect is also observed in wild type strains where the degradation of the rpsO mRNA is mostly carried out by RNase E. It must be recalled here, that the RNase E and PAP I dependent pathways are somehow related and can substitute for one another [41].

\section{Hfq does not affect translation and autoregulation of the rpsO mRNA}

Since mRNAs are generally protected by translating ribosome, we reasoned that the stabilization of the rpsO transcript in the Hfq deficient strains may result from an increase in translation efficiency. One could imagine that the autoregulation loop which adjusts $r p s O$ translation efficiency to the need for S15, may convert the drop in mRNA resulting from Hfq deficiency into a stimulation of translation aiming to compensate for the poor levels of S15 synthesis. Alternatively, Hfq-mRNA interactions could directly affect translation or the autogeneous repression by S15.

These hypotheses led us to look at the behaviour of the constitutively translated rpsO transcript, which does not bear the operator recognizable by S15 and hence whose translation is independent of the S15 yield. This was achieved by using a plasmid-borne $r p s O$ gene in which the first 122 nucleotides of the coding region were deleted, seven of these nucleotides being involved in the formation of the translational operator. This plasmid, referred to as $\mathrm{p} \Delta \mathrm{S} 15 \mathrm{AUG}$, encodes a truncated S15 polypeptide unable to participate in the $30 \mathrm{~S}$ assem-

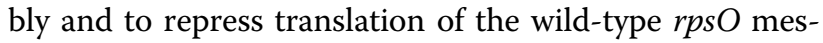
sage [38]. The stabilities of mRNAs originating from the chromosome $(r p s O)$ and from the plasmid $(r p s O \Delta)$ were determined in $h f q^{+}$and $h f q 1$ backgrounds. As was shown previously in wild-type cells the constitutively translated $\operatorname{rps} O \Delta$ transcript was more stable than the native $r p s O$ mRNA due to higher translation levels [38]. The greater stability of the rpsO $\Delta$ transcript was also observed in the $h f q$ mutant (Table 1). Moreover, just as in the case of the wild-type $\operatorname{rps} O$ mRNA transcript originating from the chromosome, Hfq inactivation caused both a drop in the rpsO $\triangle$ mRNA level and an increase in its stability (Table 1). These data indicate that the consequences of Hfqdeficiency on mRNA level and stability do not rely on the autoregulation of S15 synthesis. Indeed, the observed stabilization of the unregulated rpsO $\triangle$ mRNA in the $h f q$ mutant rules out the possibility that a drop in a functional rpsO mRNA concentration provokes increased translation efficiency through the autoregulation loop, resulting in stabilization of mRNA.

Whether Hfq affects the autoregulation of the genuine rps $O$ mRNA bearing an intact $r p s O$ operator recognizable by $\mathrm{S} 15$ was directly examined by using a specially generated strain in which the $\operatorname{rps} O$ promoter and the whole translation initiation region (TIR) governed synthesis of the chimeric $\beta$-galactosidase from the chromosomal lacZ gene. The $h f q^{+}$and $h f q^{-}$isogenic variants of this strain were obtained by $\mathrm{P} 1$ transduction, and then each of them was transformed by a plasmid, pS15, expressing the $\mathrm{rps} O$ gene from its own promoter and thereby serving as a source of additional S15 in a cell, or by a parent vector pACYC184 as a control. The $\beta$ galactosidase assay showed that neither the expression of the translationally active gene fusion (cells transformed by pACYC184) nor that of the translationally repressed fusion (cells transformed by $\mathrm{pS} 15$ ) were modified by the $h f q$ mutation (Fig. 3A). Indeed, the impact of $\mathrm{S} 15$ protein expression in trans on the rpsO-lacZ fusion was similar in both $h f q^{+}$and $h f q$ deficient strains (in both cases the repression factor was about 9-10) (Fig. $3 \mathrm{~A})$. Thus, Hfq does not seem to be involved in the autogeneous control of S15 synthesis.

As one can notice (Fig. 3B), the reduction of the rpsO mRNA level in the $h f q^{-}$strain is more pronounced in strains with empty vector (lanes 1 and 4) than for the pS15 bearing strains (lanes 2 and 5) indicating that the gene dose plays a role in this effect. As expected, the drop in the rpsO mRNA abundance was complemented by the plasmid pTX381 (pHfq), a pACYC 184-derivative expressing the wild-type $h f q$ gene from its own promoter.

It is important to note that the changes in abundance and stability of the rpsO transcripts do not depend on the 

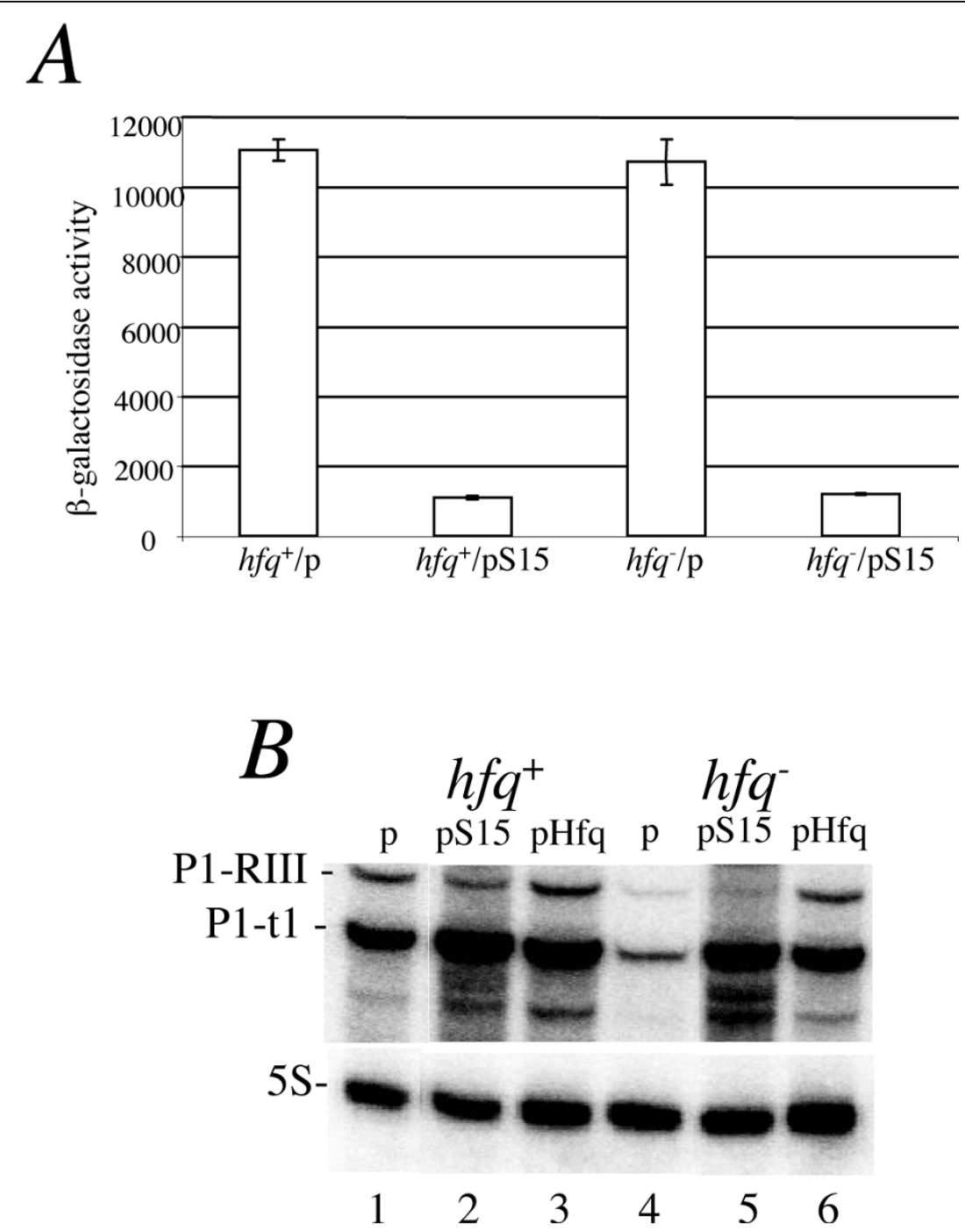

Figure $3 \mathrm{Hfq}$ is not implicated in autogeneous repression of the rpsO mRNA by S15. (A) $\beta$-Galactosidase activities of the rpsO'-'lacZ chromosomal fusion in the $h \mathrm{hq}^{+}$and $h f q \Delta$ derivatives of strain IBrpsO188://acZ (Materials and methods) carrying plasmids pACYC184 (p) and its derivative pS15 expressing the rpsO gene. (B) Northern-blot analysis of the rpsO mRNA in strain IBrpsO188::lacZ transformed with pACYC184 (p) and its derivatives pS15 and pHfq (pTX381). Lower panel shows the amount of 5S RNA per lane. RNA was extracted from cells grown at $37^{\circ} \mathrm{C}$ to $\mathrm{OD}_{600} \approx 0.4$ in LB supplemented with chloramphenicol $(34 \mu \mathrm{g} / \mu \mathrm{l})$.

nature of the inactivating mutation. We found that inactivation of the $h f q$ gene by insertion of a $\Omega$-cassette $(h f q 1)$ or by in-frame deletion $(h f q \Delta)$ had similar impacts. In contrast, the V43R substitution, which only partially impairs Hfq function [16] did not significantly affect the amount of the rps $O$ mRNA in the cell, indicating that complete Hfq deficiency is required for the reduction (Fig. 4).

\section{Hfq selectively affects abundance of several transcripts} In order to determine whether the effect of $\mathrm{Hfq}$ deficiency on the rpsO mRNA could be also observed for other transcripts, we probed total RNA isolated from cells containing wt and mutant $h f q$ alleles for $r p s T, r p s B$ and lpp mRNAs and for the Leu1 and MetY2 tRNAs.
While it has been reported that $\mathrm{Hfq}$ binds the $\operatorname{rps} \mathrm{O}$ mRNA $[16,29]$ and tRNAs $[18,19]$ in vitro, the other three transcripts were not examined. However, the fact that mRNAs from many ribosomal protein operons coimmunoprecipitate with Hfq [20] argues in favor of such a possibility for rpsB and rpsT. The Northern blots revealed that $h f q$ inactivation did not modify lpp mRNA or tRNA abundance (Fig. 4). In contrast, the two rpsT mRNA species were less abundant in the $h f q$ mutant, the stronger effect being observed for the P2-t1 rpsT transcripts initiated at promoter P2. Just as in the case of $r p s O$, the decreased level of $r p s T$ transcripts was accompanied by a significant increase in their stability (Table 1). 


\title{
喜意焉焉
}

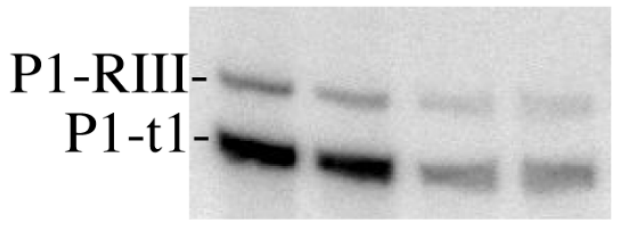

$\operatorname{rpsO}$

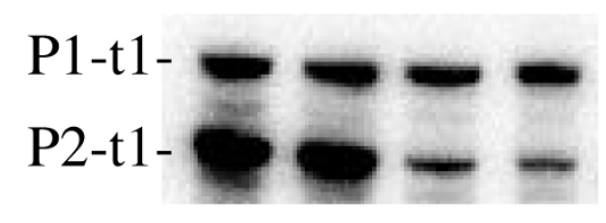

$\operatorname{rps} T$

\author{
rpsB-tsf- \\ rps $B$
}

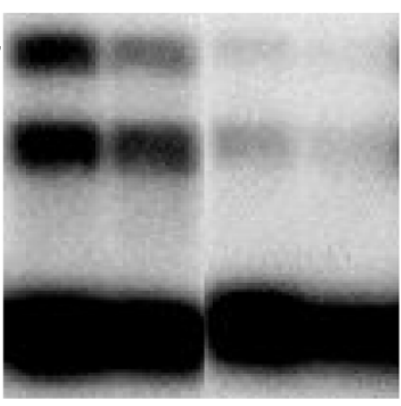

$\operatorname{rps} B$

$+$

$5 S$

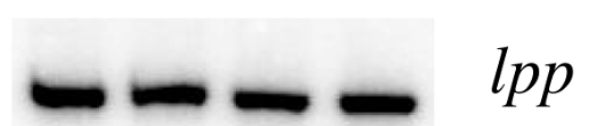



tRNAleu



Figure $4 \mathrm{Hfq}$ inactivation affects levels of some but not all transcripts. Total RNA from strains N3433 (hfq ${ }^{+}$), IBPC941 (hfqV43R), IBPC929 ( $h f q 1)$, IBPC953 ( $h f q \Delta)$ were analysed on Northern blot probed for rpsO, rpsT, rpsB, Ipp, tRNA leu, tRNA fMetY2 and 5 S rRNA

Transcripts of the rpsB-tsf operon also behave like the $r p s O$ transcripts in response to $\mathrm{Hfq}$ deficiency. The $r p s B$ and rpsB-tsf mRNAs are transcribed from a single rpsB promoter [43]. The monocistronic rps $B$ transcripts terminate at the attenuator structure in front of $t s f$, while about one third of the total transcripts read through the attenuator, generating the bicistronic rpsB-tsf mRNA. The levels of both transcripts were significantly decreased by Hfq deficiency (Fig. 4, 5). Moreover, like in the case of the rpsO-lac $Z$ transcript, the abundance of the chimeric rpsB-lac $Z$ mRNA (the transcription product from a rpsB-lac $Z$ translational fusion whose expression was driven by the $\operatorname{rps} B$ promoter and the $r p s B$ TIR) was also lower in the absence of Hfq in a cell (Fig. 5). Because the rpsB-lacZ construction used in these experiments bears a small deletion in the $\operatorname{rps} B$ 




Figure 5 Negative impacts of Hfq deficiency on abundance of the rpsO-lacZ and rpsB-lacZ. Preparations of total RNA from strains

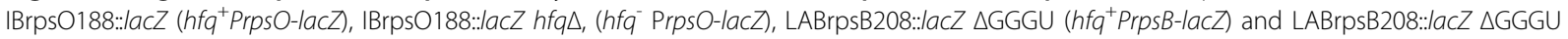
hfq $\triangle$ (hfa" PrpsB-lacZ) were analyzed on Northern blot and probed for rpsB, lacZ and 5S.

TIR, which abolishes autogeneous regulation by $\mathrm{S} 2$ in trans [43], this effect is not related to changes in translation control.

Interestingly, the rpsB-lac $Z$ fusions produced similar level of $\beta$-galactosidase activity in $h f q^{+}$and $h f q \Delta$ isogenic strains $(12150+/-400$ and $11800+/-250$ units of $\beta$ galactosidase in the $h f q^{+}$and $h f q \Delta$ strains respectively). The same was observed for the rpsO-lacZ fusion (Fig. $3 \mathrm{~A})$, where the $ß$-galactosidase activities in $h f q^{+}$and $h f q^{-}$ strains were similar. This means that despite the reduced levels of both mRNAs (rpsB-lacZ and rpsOlac $Z$ ) in $h f q^{-}$mutant, the relative levels of the corresponding proteins remain about the same, indicating that the reduction in mRNA concentration may be compensated by an increase of translation efficiency or by other compensatory mechanisms. The reduced levels of many transcripts for important cellular proteins (ribosomal proteins, translation factors and others) were observed in a genome-wide transcriptome analysis of a $h f q$ mutant by Guisbert et al. [12]. The drop in levels of the transcripts encoding ribosomal proteins may slow down ribosome synthesis, thereby being responsible (at least partly) for the known growth defects of the $h f q$ mutants. In turn, the slower rate of ribosome synthesis should slow down the synthesis of other cellular proteins, so that finally the overall proteome of essential proteins is kept in balance. Thus, as revealed by Western-blotting (Fig. 6), the relative amounts of the $ß$ galactosidase produced from the rpsO-lac $Z$ fusion gene and polynucleotide phosphorylase (encoding by the $p n p$ transcripts whose level, as will be shown below, is independent of the presence of $\mathrm{Hfq}$ ) remain about the same in $h f q^{+}$and $h f q^{-}$strains despite a large reduction in the rpsO-lac $\mathrm{Z}$ transcript level caused by $\mathrm{Hfq}$ deficiency.

\section{Transcription of the pnp gene from its own promoter is not sensitive to $h f q$ deletion}

Since the above data suggest that changes in mRNA steady-state levels cannot be caused by modifications of mRNA stability or translation efficiency, we suspected that the lack of Hfq might exert a direct negative impact on transcription yield. Previous data have shown that Hfq may act as a DNA binding protein [30] that is able to change superhelicity of plasmid DNA [5]. Thus the 


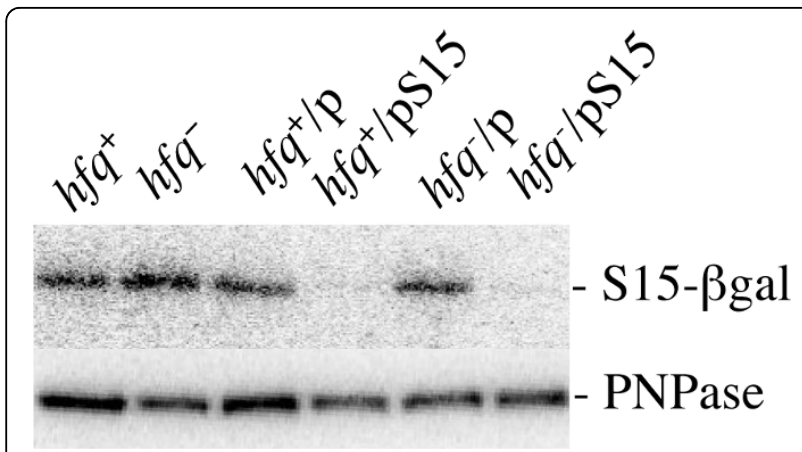

Figure 6 Balanced production of proteins encoded by the rpsO-lacZ and pnp genes in $h f q^{+}$and $h f q^{-}$backgrounds. PNPase and $\beta$-Galactosidase levels were determined by Western-blotting in the $h f q^{+}$and $h f q \Delta$ derivatives of strain IBrpsO188:IacZ, bearing the rpsO'-lacZ chromosomal fusion (Materials and methods) and carrying plasmids PACYC184 (p) or its derivative pS15 expressing the $\mathrm{rps} O$ gene.

changes in transcription yield observed in the absence of Hfq could be the consequence of modified DNA topology. If this is the case, the loss of Hfq should change the levels of the pnp mRNA, whose transcription from its own P2 promoter was reported to depend on DNA supercoiling [44]. The relative abundance of the pnp transcripts was deduced from the amounts of cDNA generated by primer extension. Since the $p n p$ mRNA is strongly destabilized by a RNase III cleavage in the 5 ' UTR [34], these experiments were also performed in a RNase III deficient strain ( $r n c$ mutant) where RNA concentration is expected to reflect the transcription efficiency of pnp more directly. Fig. 7 shows that $\mathrm{Hfq}$ deficiency has no detectable effect on the intracellular concentrations of either the primary transcript initiated at P2 or the transcript processed by RNase III. This contrasts with the bands referred to as M2 and $t$ at the top of the autoradiograph (Fig. 7) which correspond to arrest of reverse transcription at an RNase E processing site and a stable hairpin in the rpsO-pnp bicistronic transcript initiated at the $r p s O$ promoter (P1). Both bands diminished in intensity in $h f q$ strain, confirming the decrease in abundance of transcripts from the rpsO promoter observed by Northern-blot technique. Thus, the lack of $\mathrm{Hfq}$ affects transcription yield only from a subset of promoters (e.g. $r p s O, \operatorname{rps} B, \operatorname{rps} T$ ), and this negative effect is unlikely to result from changes in DNA topology. Finally, PNPase was used as a control to verify that Hfq does not globally affect protein synthesis (see above).

\section{Discussion}

The experiments described above show that Hfq deficiency may cause modifications of both mRNA abundance and stability, but these effects are not related.

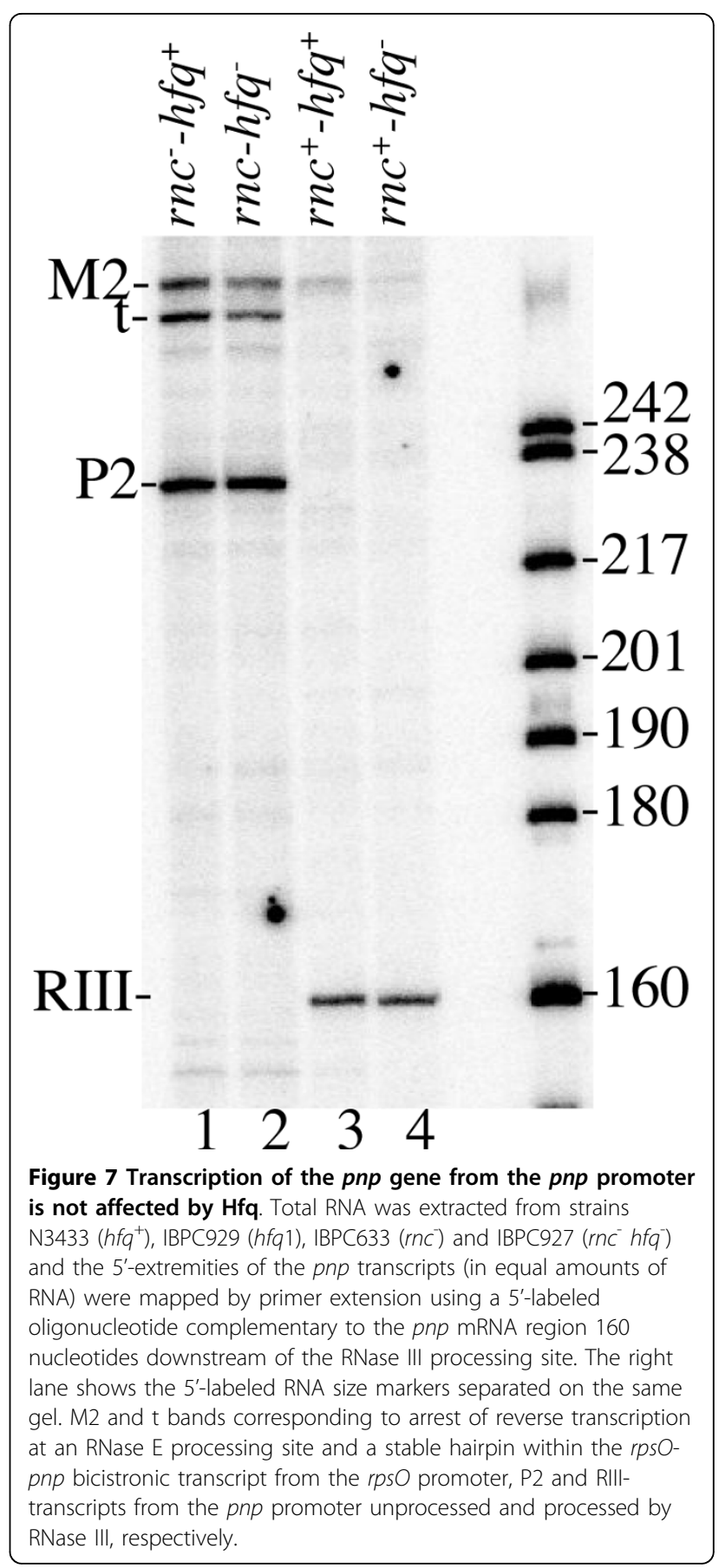

Indeed, stabilization of the rps $O$ mRNA takes place even in the absence of translational regulation, which presumably occurs in response to a drop in mRNA levels in the cell, and the decrease in mRNA concentration is accompanied by RNA stabilization expected to cause its accumulation. The requirement of PAP I activity for both stabilization and decrease of $r p s O$ transcripts upon $\mathrm{Hfq}$ inactivation suggests that polyadenylation and $\mathrm{Hfq}$ act synergistically. The fact that mRNA stabilization in 
the absence of Hfq is only observed if PAP I is active might be explained by assuming that Hfq can no longer stimulate the elongation of oligo(A) extensions used as recognition sites by exoribonucleases. At the same time, the competition between Hfq and RNase E for the same site on the rpsO mRNA, which was observed in vitro [29], does not seem to play a role in the control of mRNA degradation under conditions of exponential growth in rich medium (growth conditions used in our experiments): indeed, the RNase E pathway of decay is not affected by $\mathrm{Hfq}$ inactivation. We cannot explain right now why Hfq has a significant impact on the $r p s O$ mRNA abundance if PAP I is active. Nevertheless, the data above showing that the drop in rpsO mRNA concentration does not result from Hfq-mediated posttranscriptional events led us to the conclusion that it may reflect a negative impact of the loss of Hfq on transcription yield.

Recent microarray analysis revealed down-regulation of many ribosomal protein ( $r$-protein) operons caused by lack of $\mathrm{Hfq}$ [12]. Moreover, earlier work also reported the co-immunoprecipitation of $\mathrm{Hfq}$ with mRNAs of r-protein operon in $h f q^{+}$cells, and their general loss in $h f q$ mutants [20]. No plausible explanation for these effects was proposed. The implication of Hfqdependent ncRNAs in positive regulation of house-keeping genes is very unlikely. The finding that a similar negative impact on abundance of the $\operatorname{rps} O$ and $\operatorname{rps} B$ transcripts (Fig. $3 \mathrm{~B}$ and 4 ), on one hand, and on the corresponding reporter constructs rpsO-lacZ and rpsB-lac Z (Fig. 5), on another hand, implies that the observed reduction of the steady-state RNA level in $h f q^{-}$strains may result from changes in promoter recognition or other early steps of transcription.

It is unlikely that Hfq discriminates promoters directly. However, there remains a possibility that Hfq may affect promoter recognition indirectly. The E. coli RNA polymerase holoenzyme is composed of the core enzyme (consisting of $\alpha 2, \beta, \beta^{\prime}$ and $\omega$ subunits) tightly bound with one of seven $\sigma$ subunits which determine sequence specific contacts with promoter DNA. While the level of the housekeeping $\sigma^{70}$ subunit is constant under all growth conditions, the intracellular concentrations of the six other $\sigma$ subunits vary as a function of the growth phase, growth conditions and upon exposure to environmental stress [45]. There is considerable evidence for competition between sigma factors for core RNA polymerase in vivo; therefore alterations in the level of one sigma factor may influence the competitor properties of others $[46,47]$. At least two sigma factors, $\sigma^{\mathrm{S}}$ and $\sigma^{\mathrm{E}}$, are affected by Hfq inactivation, indicating that the relative abundance of different holoenzymes varies between $h f q^{+}$ and $h f q^{-}$strains. Hfq deficiency decreases rpoS $\left(\sigma^{\mathrm{S}}\right)$ expression at the translational level $[4,48]$. At the same time the rpoE mRNA encoding $\sigma^{\mathrm{E}}$ is up-regulated in a $h f q$ mutant [12], thus enhancing the competitiveness of $\sigma^{\mathrm{E}}$ for the core RNA polymerase. However, the transcription of pnp as that of the tRNA genes, all of which are insensitive to Hfq deficiency (Fig. 4 and 7), are $\sigma^{70}$ dependent, arguing against the possibility that competition between sigma factors is responsible for the downregulation of the r-protein mRNAs. Alternatively, it is possible that Hfq-mediated modulation of transcription may occur at an early elongation step. Indeed, during the past decade, transcription elongation has been appreciated as a regulated phase of transcription. Regulation of transcript elongation occurs mainly due to transcriptional pausing that can be stabilized by several mechanisms: hairpin-dependent pausing (e.g. well-characterized his leader pause site), backtracked pauses, and $\sigma$-stabilized RNA polymerase stalling downstream from promoters [49-53]. As concerns the potential role of Hfq in regulation of transcript elongation via hairpin-dependent pausing, most pause signals have been found in the leader regions of certain amino acid biosynthetic operons. The reported co-immunoprecipitation of Hfq with mRNAs encoding leader peptides of these operons may be indicative of a role of Hfq in modulating attenuation [20]. Moreover, this role should be positive, as microarray analysis revealed that lack of Hfq decreased the levels of mRNAs implicated in threonine $(\operatorname{th} r A B C)$ or histidine (his $G, D, C, B, H$ ) biosynthesis pathways regulated by attenuation [12].

The positive role for $\mathrm{Hfq}$ in transcription in vivo we propose here is consistent with a reported stimulatory effect of $\mathrm{Hfq}$ on the overall yield of transcription in vitro [23]. Hfq may play a chaperoning role in co-transcriptional folding of a nascent RNA chain, counteracting transcription pausing or arrest and preventing premature release of the transcript. Biologically important RNAs often solve their folding problem using the assistance of chaperone and cofactor proteins [54]. In this respect, it should be mentioned that folding of long structured mRNA leaders of the $r p s O$ and $r p s B$ operons plays a crucial role in regulation of their expression $[43,55]$. In addition to the folding problems, transcriptional pauses within the mRNA leaders of $r$-protein mRNAs may also be stabilized by rebinding of $\sigma^{70}$ to the elongating RNA polymerase, when -10-like elements located downstream from promoters are exposed in transcriptional bubble [50,52,53]. Indeed, -10-like elements followed by three GC base pairs (consensus for $\sigma^{70}$-dependent pausing) are easily recognized within the rpsO (TACACTGGG, positions +40 to +48 from transcription start) and rpsB (TAATATGGG, positions +110 to +118$)$ mRNA leaders. Taking this into account, it is tempting to suppose that Hfq may play a positive role in the co-transcriptional folding and/or maintaining of 
the nascent RNA chain during transcriptional pauses, preventing transcription arrest and formation of abortive elongation complex. If this is the case, the portion of abortive transcription on the pause-inducing sites should increase in the absence of Hfq in the cell, leading to a reduced steady-state level of the mRNAs produced. The mRNA transcripts that escape abortive events will be less abundant but more stable either because they are translated more efficiently to produce sufficient amount of $r$-proteins for ribosome biosynthesis, or due to inefficiency of poly(A)-dependent degradation pathway mediated by Hfq. We believe that the proposed here potential role of $\mathrm{Hfq}$ in maintaining nascent transcripts to prevent premature transcript release at the pausing sites is the most plausible explanation for the observed down-regulation of r-protein mRNAs in $h f q$ null-mutants.

\section{Conclusions}

We present here several lines of evidence indicating that rpsO, rpsB, rpsB-tsf and rpsT mRNAs are down-regulated in $h f q$ null mutants and that the reduction of the mRNA levels upon Hfq deficiency cannot be explained by destabilization of mRNAs and relates rather to changes in transcription efficiency. Our results provide an explanation for the recent microarray analysis which has revealed down-regulation of several ribosomal protein ( $r$-protein) operons caused by the lack of Hfq. Taken together, Hfq appears to have a much greater role in RNA metabolism than previously anticipated involving all the steps of an RNA molecule's "life", from its synthesis to its degradation.

\section{Methods}

\section{Bacterial strains and plasmids}

The name and origin of the strains used here are listed in Table 2. A DNA fragment comprising the rpsO regulatory regions $\operatorname{rps} O$ promoter and translation initiation region, positions from -188 to +58 with respect to $A+1$ in the initiator ATG) was amplified from the genomic $E$. coli DNA and inserted into pEMBL $\Delta$ 46/BamHI, HindIII in frame with the lac $Z$ coding sequence [56]. Primers used for PCR amplification were: PrpsO-for 5'-

CGTGGATCCTCGTCGCCTGGTGGTTG corresponding to the sequence from -188 to -162 upstream of rpsO and bearing the BamHI site near the 5'-terminus (italicized) and TIRrpsO-rev 5'-CAGAAGCTTGCGTCACGACCAAACTC complementary to the rpsO coding sequence from +40 to +58 and bearing the HindIII site (italicized). The resulting plasmid pErpsO188 was then used to create the ENSO derivative IBrpsO188:: lacZ by homologous recombination [56]. This strain was used to generate two tetracycline-resistant derivatives $h f q^{+}$and $h f q \Delta$ by $\mathrm{P} 1$ transduction as described [16].
Table 2 Escherichia coli strains and plasmids used in this work

\begin{tabular}{|c|c|c|}
\hline Strain or plasmid & Relevant characteristics & $\begin{array}{l}\text { Reference/ } \\
\text { source }\end{array}$ \\
\hline \multicolumn{3}{|l|}{ Strains } \\
\hline N3433 & HfrHlacZ43 relA1 spoT1 thi-1 & D. Apirion \\
\hline N3431 & N3433 rne3071(ts) & D. Apirion \\
\hline IBPC633 & N3433 rnc105 & {$[34]$} \\
\hline IBPC903 & N3433 $\Delta p c n B\left(\operatorname{kan}^{R}\right)$ & {$[58]$} \\
\hline IBPC927 & IBPC633 hfq 1:: $\Omega\left(\right.$ kan $^{\mathrm{R}}$, Bcll) & this work \\
\hline IBPC928 & N3431 hfq 1:: $\Omega\left(\operatorname{kan}^{\mathrm{R}}, \mathrm{Bcll}\right)$ & this work \\
\hline IBPC929 & N3433 hfq 1:: $\Omega\left(\operatorname{kan}^{\mathrm{R}}, \mathrm{Bc} / \mathrm{l}\right)$ & {$[16]$} \\
\hline IBPC941 & N3433 hfqV43R cycA30::Tn10 & {$[16]$} \\
\hline IBPC953 & N3433 hfa $\Delta 22-294$ сусA30::Tn10 & {$[16]$} \\
\hline IBPC981 & IBPC903 hfq $\triangle 22-294$ cycA30::Tn10 & this work \\
\hline ENSO & HfrG6lacZ $\triangle 12$ & {$[56]$} \\
\hline IBrpsO188::IacZ(*) & ENSO rpsO'-lacZ & this work \\
\hline \multirow{2}{*}{$\begin{array}{l}\text { LABrpsB208 } \triangle \mathrm{GGGU} \\
\left(^{*}\right)\end{array}$} & ENSO rpsB'-'IacZ bearing deletion in & \\
\hline & rps $B$ TIR from -72 to -69 & {$[43]$} \\
\hline \multicolumn{3}{|l|}{ Plasmids } \\
\hline $\mathrm{p} \triangle \mathrm{S} 15 \mathrm{AUG}$ & $\begin{array}{l}\text { pCL1921 derivative expressing } \\
\Delta r p s O\end{array}$ & {$[38]$} \\
\hline pACYC184 & Tet $^{r}, \mathrm{Cm}^{r}$ & {$[59]$} \\
\hline pS15 & $\begin{array}{l}\text { pACYC184 derivative expressing } \\
\text { rpsO }\end{array}$ & this work \\
\hline pGEM3 & $A m p^{r}$ & $\begin{array}{l}\text { Promega } \\
\text { corp. }\end{array}$ \\
\hline pTX367 (**) & pGEM3 derivative expressing hfa & {$[5]$} \\
\hline pTX381 (**) & pACYC184 derivative expressing hfa & {$[5]$} \\
\hline
\end{tabular}

$(*)$ Tetracyclin-resistant derivatives of these strains, bearing cycA30::Tn10 and hfq $\Delta 22-294$ cycA30::Tn 10, were constructed for using in this work. (**) These two plasmids contain the same insert. They were used without distinction assuming that the same amount of $\mathrm{Hfq}$ is overproduced due to autoregulation $[16,17]$.

The plasmid pS15 was created by cloning the whole rps $O$ gene flanked with its own promoter and terminator into BamHI and HindIII sites of pACYC184. The DNA fragment to be cloned was generated by PCR on E. coli genomic DNA using rpsO-for corresponding to the positions $(-149)$ to $(-126)$ relative to the $r p s O$ translation start and bearing the BamHI site; 5'-CAGGGATCCGTCTTGCGATAACAG and rpsO-rev, complementary to the positions from +303 to +325 of the rpsO mRNA and bearing the HindIII site 5'CCGTAAGCTTGAAAAAAGGGGCC.

Construction of strains LABrpsB208::lacZ carrying chromosomal rpsB'-'lac $Z$ fusion with the rpsB portion comprising the rps $B$ promoter and TIR (positions from -208 to +41 relatively the initiator ATG codon) was described [43]. Here, we used a derivative of this strain, LABrpsB208::lacZ $\triangle$ GGGU bearing a small deletion in the rpsB 5'-untranslated region (from -72 to -69 ), which abolishes autoregulation [43]. The $h f q \Delta$ allele [16] was 
transferred into this derivative by $\mathrm{P} 1$ transduction to generate $h f q^{+}$anf $\Delta h f q$ variants.

\section{Cell growth and $\beta$-galactosidase assay}

In the case of IBrpsO188::lac $Z$ and LABrpsB208::lacZ, cell cultures were grown at $37^{\circ} \mathrm{C}$ in $\mathrm{LB}$ medium supplemented if necessary with tetracycline $(12 \mu \mathrm{g} / \mathrm{ml})$ or chloramphenicol $(35 \mu \mathrm{g} / \mathrm{ml})$, in the absence of IPTG (lac-promoter is closed, rps $O$ or rpsB promoters are active). Cells were harvested in exponential phase $\left(\mathrm{OD}_{600} \approx 0.4-0.5\right)$. The $\beta$-galactosidase activity was measured in clarified cell lysates [54] and expressed in nmol ONPG (o-nitrophenyl-b-D-galactopiranoside) hydrolysed per minute per milligram of total soluble proteins. Protein concentration in lysates was measured by Bradford assay (Bio-Rad).

\section{Western blotting}

Cellular proteins $(20 \mu \mathrm{g})$ were separated on a $12 \%$ SDSPAGE gel and analyzed with the use of ${ }^{125}$ I-iodinated A-protein as described in [16]. Polyclonal rabbit antibodies raised against $\beta$-galactosidase (ICN Biomedicals, Inc.) and PNPase (kindly provided by A. J. Carpousis) were used.

\section{RNA extraction and analysis}

RNAs were prepared form bacteria grown to an $\mathrm{A}_{650}=$ 0.35-0.4, according to [37]. Templates for the synthesis of rps $O$ and rpsT RNA probes were obtained by PCR amplification as described [57]. The lacZ template was obtained using TAATACGACTCACTATAGGGATACTGACGAAAC and GCCGTCGTTTTACAACGTC, the $l p p$ probe using TAATACGACTCACTATAGGGTATTTAGTAGCCATGTTG and GTTCTACTCTGCTGGCAG, and the rpsB probe using TAATACGACTCACTATAGGGTTCACGAAGAACTGGTCG and ATGGCAACTGTTTCCATGCG oligonucleotides as primers. The upstream primer includes the T7 promoter indicated in italics. RNA probes were synthesized by T7 RNA polymerase yielding uniformly labeled RNAs with $\left[\alpha-{ }^{32} \mathrm{P}\right]$ UTP [26]. 5S rRNA, tRNALeu1 and tRNAMetY were probed with the 5'labelled oligonucleotides 5'-ACTACCATCGGCGCTACGGC, 5'-CCCCCACGTCCGTAAGGACA and 5'CGGGTTATGAGCCCGACGA, correspondingly.

Total RNA separation on 1\% agarose formaldehyde gel or acrylamide/urea gel and Northern blotting were previously described $[34,35]$. RNA levels were quantified using a PhosphoImager, and values were corrected for variations in RNA loading by hybridizing the same blot for the 5S rRNA.

\section{Acknowledgements}

We are grateful to A. Kolb and C. Condon for discussion and reading the manuscript. We are indebted to C. Pennetier who contributed to this work at early stage. We thank M.E. Winkler and A.J. Carpousis for supplying plasmids and antibodies. This work was supported by the Centre National de la Recherche Scientifique (UPR 9073) and Paris VII University (France). IB was supported by University Paris VII as a visiting scientist and by RFBR grant 06-04-48353.

\section{Author details}

1UPR CNRS n 9073, conventionnée avec I'Université Paris 7 - Denis Diderot Institut de Biologie Physico-Chimique, 13 rue Pierre et Marie Curie, 75005 Paris, France. ${ }^{2}$ Shemyakin-Ovchinnikov Institute of Bioorganic Chemistry, Russian Academy of Sciences, 117997 Moscow, Russia.

\section{Authors' contributions}

$J L D, I V B$ and EH performed all presented experiments, IVB and EH conceived the study and analyzed the data. IVB, PR and EH wrote the manuscript. All authors read and approved the final manuscript.

Received: 19 August 2009

Accepted: 18 February 2010 Published: 18 February 2010

\section{References}

1. Franze de Fernandez MT, Hayward WS, August JT: Bacterial proteins required for replication of phage $\mathrm{Q} \beta$ ribonucleic acid. J Biol Chem 1972, 247:824-821.

2. Valentin-Hansen $P$, Eriksen M, Udesen C: The bacterial Sm-like protein Hfq: a key player in RNA transactions. Mol Microbiol 2004, 51:1525-1533.

3. Sun X, Zhulin I, Wartell RM: Predicted structure and phyletic distribution of the RNA-binding protein Hfq. Nucleic Acids Res 2002, 30:3662-3671.

4. Muffler A, Traulsen DD, Fischer D, Lange R, Hengge-Aronis R: The RNAbinding protein HF-1 plays a global regulatory role which is largely, but not exclusively, due to its role in expression of the $\sigma^{\mathrm{s}}$ subunit of RNA polymerase in Escherichia coli. J Bacteriol 1997, 179:297-300.

5. Tsui H-C, Leung H-C, Winkler ME: Characterization of broadly pleiotropic phenotypes caused by an hfq insertion mutation in Escherichia coli K-12. Mol Microbiol 1994, 13:35-49.

6. Moller T, Franch T, Hojrup P, Keene D, Bächinger HP, Brennan RG, ValentinHansen P: Hfq: a bacterial Sm-like protein that mediates RNA-RNA interaction. Mol Cell 2002, 9:23-30.

7. Kawamoto $H$, Koide $Y$, Morita $T$, Aiba $H$ : Base-pairing requirement for RNA silencing by a bacterial small RNA and acceleration of duplex formation by Hfq. Mol Microbiol 2006, 61(4):1013-1022.

8. Zhang A, Wassarman KM, Ortega J, Steven AC, Storz G: The Sm-like HFq protein increases OxyS RNA interaction with target mRNAs. Molecular Cell 2002, 9:11-22.

9. Mikulecky PJ, Kaw MK, Brescia CC, Takach JC, Sledjeski DD, Feig AL: Escherichia coli Hfq has distinct interaction surfaces for DsrA, rpoS and poly(A) RNAs. Nat Struct Mol Biol 2004, 11(12):1206-1214.

10. Brown $L$, Elliott $T$ : Efficient translation of the RpoS sigma factor in Salmonella typhimurium requires host factor $\mathrm{l}$, an RNA-binding protein encoded by the hfq gene. J Bacteriol 1996, 178(13):3763-3770.

11. Figueroa-Bossi N, Lemire S, Maloriol D, Balbontin R, Casadesus J, Bossi L: Loss of $\mathrm{Hfq}$ activates the sigmaE-dependent envelope stress response in Salmonella enterica. Mol Microbiol 2006, 62(3):838-852.

12. Guisbert E, Rhodius VA, Ahuja N, Witkin E, Gross CA: Hfq modulates the sigmaE-mediated envelope stress response and the sigma32-mediated cytoplasmic stress response in Escherichia coli. J Bacteriol 2007, 189(5):1963-1973.

13. Thompson KM, Rhodius VA, Gottesman S: SigmaE regulates and is regulated by a small RNA in Escherichia coli. J Bacterio/ 2007, 189(11):4243-4256.

14. Senear AW, Steitz JA: Site-specific interaction of $\mathrm{Q} \beta$ host factor and ribosomal protein $\mathrm{S} 1$ with $\mathrm{Q} \beta$ and R17 bacteriophage RNAs. J Biol Chem 1976, 251:1902-1912.

15. Miranda G, Schuppli D, Barrera I, Hausherr C, Sogo JM, Weber H: Recognition of bacteriophage $\mathrm{Q} \beta$ plus strand RNA as a template by $\mathrm{Q} \beta$ replicase: role of RNA interactions mediated by ribosomal proteins S1 and host factors. J Mol Biol 1997, 267:1089-1103.

16. Ziolkowska K, Derreumaux P, Folichon M, Pellegrini O, Regnier P, Boni IV, Hajnsdorf E: Hfq variant with altered RNA binding functions. Nucleic Acids Res 2006, 34(2):709-720. 
17. Vecerek B, Moll I, Blasi U: Translational autocontrol of the Escherichia coli hfq RNA chaperone gene. RNA 2005, 11:976-984.

18. Lee $\mathrm{T}$, Feig AL: The RNA binding protein $\mathrm{Hfq}$ interacts specifically with tRNAs. RNA 2008, 14(3):514-523.

19. Scheibe $M$, Bonin $\mathrm{S}$, Hajnsdorf $\mathrm{E}$, Betat $\mathrm{H}$, Morl M: Hfq stimulates the activity of the CCA-adding enzyme. BMC Mol Biol 2007, 8:92.

20. Zhang A, Wassarman KM, Rosenow C, Tjaden BC, Storz G, Gottesman S: Global analysis of small RNA and mRNA targets of Hfq. Mol Microbiol 2003, 50:1111-1124.

21. Butland G, Peregrin-Alvarez JM, Li J, Yang W, Yang X, Canadien V, Starostine A, Richards D, Beattie B, Krogan N, et al: Interaction network containing conserved and essential protein complexes in Escherichia coli. Nature 2005, 433(7025):531-537.

22. Morita T, Maki K, Aiba H: RNase E based-ribonucleoprotein complexes: mechanical basis of mRNA destabilization mediated by bacterial noncoding RNAs. Genes Dev 2005, 19:2176-2186.

23. Sukhodolets MV, Garges S: Interaction of Escherichia coli RNA Polymerase with the Ribosomal Protein S1 and the Sm-like ATPase Hfq. Biochemistry 2003, 42(26):8022-8034

24. Kajitani M, Ishihama A: Identification and sequence determination of the host factor gene for bacteriophage Q $\beta$. Nucleic Acids Res 1991, 9:1063-1066.

25. Mohanty BK, Maples VF, Kushner SR: The Sm-like protein Hfq regulates polyadenylation dependent mRNA decay in Escherichia coli. Mol Microbiol 2004, 54(4):905-920.

26. Hajnsdorf E, Régnier P: Host factor Hfq of Escherichia coli stimulates elongation of poly(A) tails by poly(A)polymerase I. Proc Natl Acad Sc USA 2000, 97:1501-1505.

27. Le Derout J, Folichon M, Briani F, Dehò G, Régnier P, Hajnsdorf E: Hfq affects the length and the frequency of short oligo(A) tails at the $3^{\prime}$ end of Escherichia coli rpsO mRNAs. Nucleic Acids Res 2003, 31:4017-4023.

28. Folichon M, Allemand F, Regnier P, Hajnsdorf E: Stimulation of poly(A) synthesis by E. coli poly(A)polymerase I is correlated with $\mathrm{Hfq}$ binding to poly(A) tails. FEBS J 2005, 272:454-463.

29. Folichon $M$, Arluison V, Pellegrini $O$, Huntzinger $E$, Regnier $P$, Hajnsdorf E: The poly $(A)$ binding protein Hfq protects RNA from RNase $E$ and exoribonucleolytic degradation. Nucleic Acids Res 2003, 31(24):7302-7310.

30. Takada A, Wachi M, Kaidow A, Takamura M, Nagai K: DNA binding properties of the hfq gene product of Escherichia coli. Biochem Biophys Res Com 1997, 236:576-579.

31. Azam TA, Ishihama A: Twelve species of the nucleoid-associated protein from Escherichia coli. J Biol Chem 1999, 274:33105-33113.

32. Azam TA, Hiraga S, Ishihama A: Two types of localization of the DNAbinding proteins within the Escherichia coli nucleoid. Genes Cells 2000, 5:613-626.

33. Régnier P, Portier C: Initiation, attenuation and RNase III processing of transcripts from Escherichia coli operon encoding ribosomal protein S15 and polynucleotide phosphorylase. J Mol Biol 1986, 187:23-32.

34. Hajnsdorf $E$, Carpousis AJ, Régnier P: Nucleolytic inactivation and degradation of the RNase III processed pnp message encoding polynucleotide phosphorylase of Escherichia coli. J Mol Biol 1994, 239:439-454.

35. Régnier $\mathrm{P}$, Hajnsdorf E: Decay of mRNA encoding ribosomal protein $\mathrm{S} 15$ of Escherichia coli is initiated by an RNaseE-dependent endonucleolytic cleavage that removes the $3^{\prime}$ stabilizing stem and loop structure. $J \mathrm{Mol}$ Biol 1991, 217:283-292.

36. Hajnsdorf E, Steier O, Coscoy L, Teysset L, Régnier P: Roles of RNase E, RNase II and PNPase in the degradation of the $r p s O$ transcripts of Escherichia coli: stabilizing function of RNase II and evidence for efficient degradation in an ams-rnb-pnp mutant. EMBO J 1994, 13:3368-3377.

37. Braun F, Hajnsdorf E, Régnier P: Polynucleotide phosphorylase is required for the rapid degradation of the RNase E-processed rpsO mRNA of Escherichia coli devoid of its 3' hairpin. Mol Microbiol 1996, 19:997-1005.

38. Braun F, Le Derout J, Régnier P: Ribosomes inhibit an RNase E cleavage which induces the decay of the rpsO mRNA of Escherichia coli. EMBO J 1998, 17:4790-4797.

39. Philippe C, Eyermann F, Bénard L, Portier C, Ehresmann B, Ehresmann C: Ribosomal protein $\mathrm{S} 15$ from Escherichia coli modulates its own translation by trapping the ribosome on the mRNA initiation loading site. Proc Natl Acad SC USA 1993, 90:4394-4398.
40. Hajnsdorf E, Braun F, Haugel-Nielsen J, Regnier P: Polyadenylylation destabilizes the rpsO mRNA of Escherichia coli. Proc Natl Acad SC USA 1995, 92:3973-3977.

41. Marujo PE, Braun F, Haugel-Nielsen J, Le Derout J, Arraiano CM, Regnier P: Inactivation of the decay pathway initiated at an internal site by RNase E promotes poly(A)-dependent degradation of the rpsO mRNA in Escherichia coli. Mol Microbiol 2003, 50(4):1283-1294

42. Andrade JM, Hajnsdorf E, Regnier P, Arraiano CM: The poly(A)-dependent degradation pathway of rpsO mRNA is primarily mediated by RNase $\mathrm{R}$. RNA 2009, 15(2):316-326.

43. Aseev LV, Levandovskaya AA, Tchufistova LS, Scaptsova NV, Boni IV: A new regulatory circuit in ribosomal protein operons: $\$ 2$-mediated control of the rpsB-tsf expression in vivo. RNA 2008, 14(9):1882-1894.

44. Peter BJ, Arsuaga J, Breier AM, Khodursky AB, Brown PO, Cozzarelli NR: Genomic transcriptional response to loss of chromosomal supercoiling in Escherichia coli. Genome Biol 2004, 5(11):R87.

45. Ishihama A: Promoter selectivity control of RNA polymerase. Nucleic Acids and Molecular Biology Berlin Heidelberg: Springer-VerlagLilley FEaDMJ 1997, 11:53-70.

46. Gourse RL, Ross W, Rutherford ST: General pathway for turning on promoters transcribed by RNA polymerases containing alternative sigma factors. J Bacteriol 2006, 188(13):4589-4591.

47. Jishage M, Iwata A, Ueda S, Ishihama A: Regulation of RNA polymerase sigma subunit synthesis in Escherichia coli ; intracellular levels of four species of sigma subunit under various growth conditions. J Bacteriol 1996, 178:5447-5451.

48. Lange R, Hengge-Aronis R: The cellular concentration of the sigma S subunit of RNA polymerase in Escherichia coli is controlled at the levels of transcription, translation, and protein stability. Genes Dev 1994, 8(13):1600-1612

49. Landick R: The regulatory roles and mechanism of transcriptional pausing. Biochem Soc Trans 2006, 34(Pt 6):1062-1066.

50. Hatoum A, Roberts J: Prevalence of RNA polymerase stalling at Escherichia coli promoters after open complex formation. Mol Microbiol 2008, 68(1):17-28.

51. Artsimovitch I: Post-initiation control by the initiation factor sigma. $\mathrm{Mol}$ Microbiol 2008, 68(1):1-3.

52. Mooney RA, Landick R: Tethering sigma70 to RNA polymerase reveals high in vivo activity of sigma factors and sigma70-dependent pausing at promoter-distal locations. Genes Dev 2003, 17(22):2839-2851.

53. Mooney RA, Darst SA, Landick R: Sigma and RNA polymerase: an onagain, off-again relationship?. Mol Cell 2005, 20(3):335-345.

54. Weeks KM: Protein-facilitated RNA folding. Curr Opin Struct Biol 1997, 7(3):336-342.

55. Mathy N, Pellegrini O, Serganov A, Patel DJ, Ehresmann C, Portier C: Specific recognition of rpsO mRNA and 16S rRNA by Escherichia coli ribosomal protein $\mathrm{S} 15$ relies on both mimicry and site differentiation. Mol Microbiol 2004, 52(3):661-675.

56. Dreyfus $\mathrm{M}:$ What constitutes the signal for the initiation of protein synthesis on Escherichia coli mRNAs?. J Mol Biol 1988, 204(1):79-94.

57. Le Derout J, Regnier P, Hajnsdorf E: Both temperature and medium composition regulate RNase E processing efficiency of the $\mathrm{rpsO}$ mRNA coding for ribosomal protein S15 of Escherichia coli. J Mol Biol 2002, 319(2):341-349.

58. Joanny G, Le Derout J, Bréchemier-Baey $D$, Labas V, Vinh J, Régnier $P$, Hajnsdorf E: Polyadenylation of a functional mRNA controls gene expression in E. coli. Nucleic Acids Res 2007, 35:2494-2502.

59. Chang ACY, Cohen SN: Construction and characterization of amplifiable multicopy DNA cloning vehicles derived from the P15A cryptic. J Bacteriol 1978, 134:1141-1156.

doi:10.1186/1471-2199-11-17

Cite this article as: Le Derout et al.: Hfq affects mRNA levels independently

of degradation. BMC Molecular Biology 2010 11:17. 